\title{
A rare case of successful pregnancy outcome with giant paraovarian cyst: a case report and review of literature
}

\author{
Rajshree D. Katke*, Priyanka Pagare, Jyoti Raina, Kunalkumar Singh
}

Department of Obstetrics \& Gynaecology, Cama \& Albless Hospital, Govt. Grant Medical College, Mumbai, India

\author{
Received: 15 October 2013 \\ Accepted: 27 October 2013 \\ *Correspondence: \\ Dr. Rajshree D. Katke, \\ E-mail: drrajshrikatke@gmail.com
}

(C) 2013 Katke RD et al. This is an open-access article distributed under the terms of the Creative Commons Attribution Non-Commercial License, which permits unrestricted non-commercial use, distribution, and reproduction in any medium, provided the original work is properly cited.

\begin{abstract}
A successful outcome of a pregnancy with huge paraovarian cyst in a 29 year old female who presented with 16 weeks of gestation with ultra-sonography suggestive of huge mesenteric cyst. Pregnancy was carried till 35 weeks of gestation. Exploratory laparotomy was done where a giant paraovariancyst of size $35 \mathrm{~cm} \mathrm{x} 20 \mathrm{~cm}$ x $15 \mathrm{~cm}$, weighing $2 \mathrm{~kg}$ was found. Baby was delivered by lower segment caesarean section and cystectomy was performed.
\end{abstract}

Keywords: Paraovarian cyst, Pregnancy, Caesarean section

\section{INTRODUCTION}

Paraovarian cysts originate from the mesothelium and are presumed to be remnants of the mullerian duct and wolfian duct. ${ }^{1}$ These cysts are epithelial lined closed fluid filled cysts in adnexa adjacent to ovary and fallopian tube. These cysts have been reported in all age groups and seem to be most common in third to fifth decade of life. ${ }^{2}$ Paraovarian cysts constitute about $10 \%$ of adnexal masses. ${ }^{3}$ In sonographic view, they have the same characteristics as ovarian cysts, being differentiated by small size, adjacency to ovary and persistence. Torsion, hemorrhage or rupture in a paraovarian cyst occurs occasionally but their voluminous enlargement rarely happens that too in a gravid state is the rarest one. Herein we present a rare case of a huge paraovarian cyst in a pregnant female with a successful outcome.

\section{CASE REPORT}

20 years old female married since last 6 years, a second gravidae with previous one full term normal delivery was registered in our antenatal out patient department at 15 weeks of gestation. On examination, patient's pulse was 82 beats/minute, blood pressure-110/80 mmHg, systemic examination findings were normal. Per abdomen fundal height was 14-16 weeks, a large cyst approx. $10 \mathrm{~cm} \mathrm{x14}$ $\mathrm{cm}$ extending from pelvis to supraumbilical region on left side was palpable. Obstetric ultrasound was done suggestive of single live intrauterine gestation of mean gestational age of 15 weeks 4 days with a huge cystic lesion of size approximately $15 \mathrm{~cm}$ x $12 \mathrm{~cm}$ seen in midline extending from supraumbilical region to pelvis displacing bowel loops posteriorly, suggestive of mesenteric cyst. Subsequently MRI (magnetic resonance imaging) was done which showed large intraperitoneal inframesocolic cyst in the median and left paramedian abdomen measuring $17.4 \mathrm{~cm}$ x $8.8 \mathrm{~cm}$ x $20.1 \mathrm{~cm}$ suggestive of mesenteric cyst. The ovaries appear separate from the lesion. The small bowel loops are displaced peripherally. The transverse colon is seen to drape the anterior superior margin of lesion. The sigmoid colon is seen to abut the inferior right lateral and posterior aspects of the cyst. Patient was asymptomatic, willing to continue pregnancy, conservative management was done. At 30 weeks of gestation, patient was admitted in antenatal ward with complaints of pain in abdomen.

Ultrasound findings were suggestive of single live intrauterine gestation of mean gestational age of 29 weeks 6 days with mesenteric cyst of size $17 \mathrm{~cm}$ x $16 \mathrm{~cm}$ $\mathrm{x} 11 \mathrm{~cm}$ in left side of abdomen with cyst wall showing 
normal vascularity on doppler study. Patient had pain in abdomen on \& off which was managed with conservative management by giving analgesics, keeping watch on abdominal girth, and intention was to continue the pregnancy till term gestation. At 35 weeks of gestation, patient had complaints of labour pain, on general examination pulse 80/min, BP-110/80 $\mathrm{mmHg}$, per abdomen - fundal height was 34-36 weeks, large cyst was felt, extending from supraumbilical region to pelvis, on per vaginal examination, cervical os was $2 \mathrm{~cm}$ dilated, effacement 20-30\%, membranes were intact. As patient was in labour and ultrasonography suggestive of huge? mesenteric cyst patient was taken for laparotomy under General anesthesia. On opening the abdomen in layers, gravid uterus of 35-36 weeks size with huge cystic mass seen above and lateral side of the uterus. First the uterovesical fold was opened, lower segment caesarean section was done with delivering the baby. Baby cried well after birth with Apgar score 9 at birth. Placenta delivered completely. After delivering the baby, lower segment of uterus was sutured in two layers with vicryl no.1, uterus exteriorization done and we found a Huge paraovarian cyst of $35 \mathrm{~cm} \times 20 \mathrm{~cm} \times 15 \mathrm{~cm}$ thin walled, mobile, clear in appearance with marked vascularity, no surface growth, arising adjacently from the left tubal part and ovary, and the left tube was overstretched on the surface of cyst wall. On the postero-medial part of cyst, the left was adherent to it. The cyst was delivered out intact. The left ovary separated from the cyst wall gently with fine dissection and the ovary conserved. The base of the cyst wall was clamped, sealed with the vessel sealer and tied with free linen. Haemostasis achieved completely. The left ovary was conserved. Right tube and right ovary were healthy. There was no evidence of cyst in other areas of the abdomen. Hemostasis of lower segment caesarean section wound achieved. Abdomen closed in layers. Weight of the cyst was $2 \mathrm{~kg}$. Cyst was sent for histopathology examination, Histopathology report was suggestive of simple serous cystadenoma. Post operative period was uneventful, sutures were healthy and were removed on $9^{\text {th }}$ post operative day and patient was discharged.

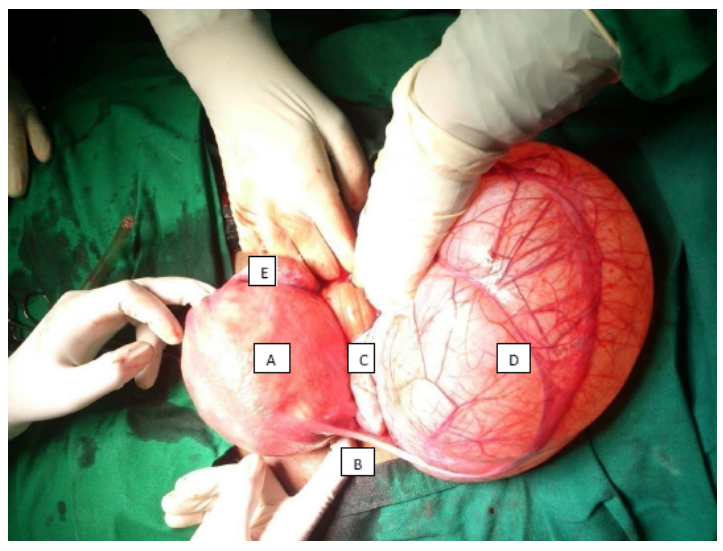

Figure 1: (A) Post caesarean uterus (B) Left fallopian tube outstretched on cyst wall. (C) Left ovary attached to the cyst wall. (D) Left paraovarian cyst (E) Right ovary.

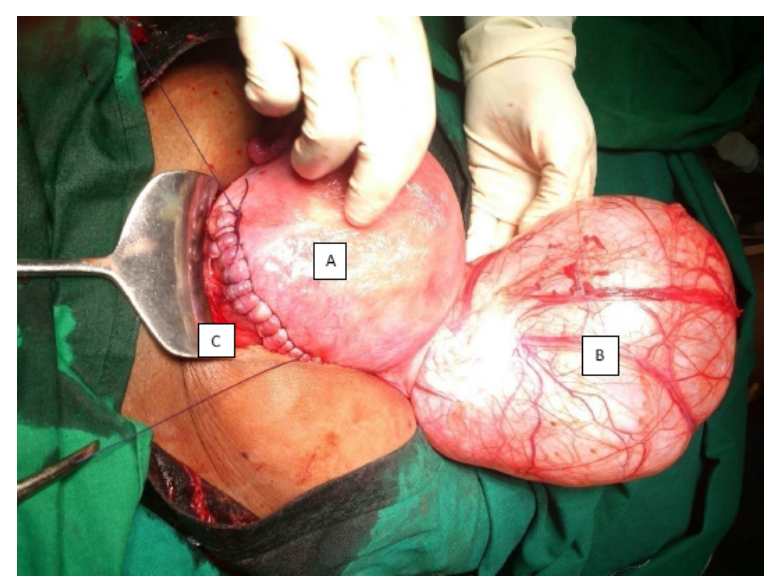

Figure 2: (A) Post caesarean uterus (B) Huge paraovarian cyst, (C) Sutured line with uterine angles.
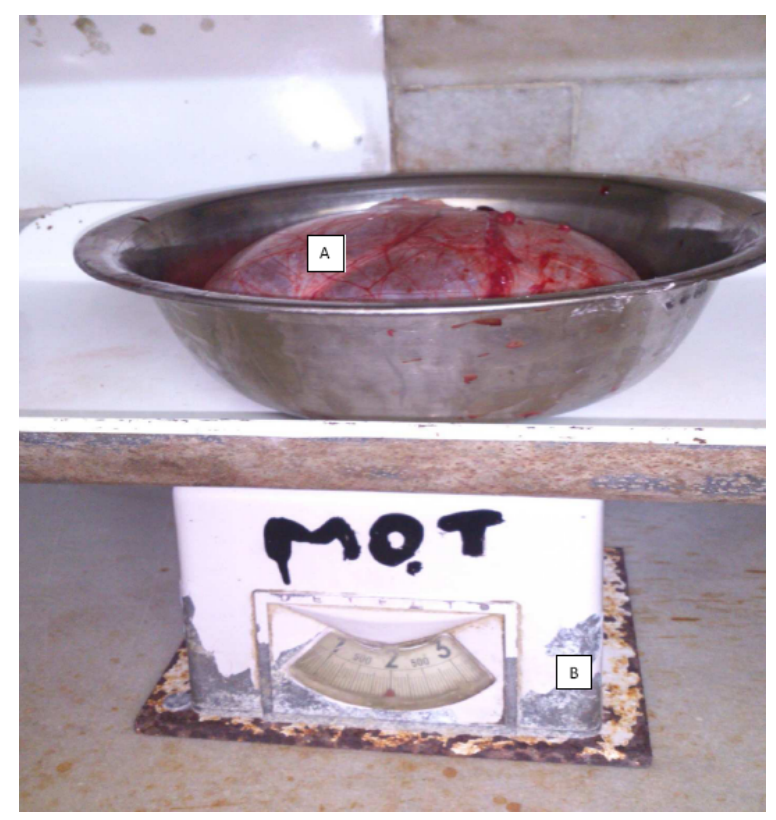

Figure 3: (A) Huge paraovarian cyst weighing 2 kg (B) Weighing scale.

\section{DISCUSSION}

Paraovarian cysts are usually small in size, typical sizes reported are 1 to $8 \mathrm{~cm}$ in diameter. ${ }^{1}$ Larger lesions may reach $20 \mathrm{~cm}$ or more in diameter and become symptomatic exerting pressure and pain symptoms in the lower abdomen. ${ }^{4}$ Large cysts can lead to torsion of the adnexa inflicting acute pain. ${ }^{4,5}$ These cysts are diagnosed as incidental finding, found at surgery or during an imaging examination that is performed for another reason but have a tendency to grow larger specially during pregnancy. Smaller lesions can be followed expectantly. Larger lesions, lesions that are growing or symptomatic, and lesions with sonographically suspicious findings (septation, papillations, fluid and solid components) are generally surgically explored and removed. Paraovarian cysts are generally benign but may, on rare occasions give rise to borderline tumours and malignancy. ${ }^{6}$ 
Malignancy has been reported in 2-3\% of cases, ${ }^{7}$ although this is rare in lesions smaller than $5 \mathrm{~cm}^{8}$ Paraovarian cysts are usually single, but bilateral lesions have been reported. ${ }^{9,10}$ Diagnostic ultrasound (sonography) is a noninvasive diagnostic imaging technique which uses high-frequency sound waves to produce images of structures within the body. The sound waves are passed through the body tissues with a device called transducer. Objects inside the body will reflect a part of sound waves back to the sensor, where the waves are recorded, analyzed and displayed for viewing on a screen. Modern sonographic equipment will display live images of moving tissues (real-time viewing) and will also provide 3-dimensional reconstruction information about different structures. The area covered by the ultrasound beam will depends on equipment design.

Doppler sonography (duplex Doppler sonography) will enable the visualization of blood flow in both arteries and veins (vascular systems) as well as in organs. It reveals changes in the pitch of sound waves (Doppler effect) as they bounce off circulating blood cells. When combined with the technology of advanced data processing, color Doppler can acquire data fast enough to study the complex flow of blood in the heart and other organs. A computer image will represents the speed and direction of blood flow is then generated from the data. Power Doppler sonography is a new technique is about 5 times more sensitive than color Doppler. It is useful in measuring the blood flow in blood vessels traversing solid organs.

Our case is a rarest case of huge paraovarian cyst associated with pregnancy, which was continued till 35 weeks of gestation and with surgical expertise could result in successful outcome.

\section{CONCLUSION}

Paraovarian cysts are rare and its diagnosis on imaging is challenging considering gravid uterus with paraovarian cyst. As in our case it was diagnosed as mesenteric cyst on ultrasound and MRI but it was turned out to be huge left ovarian cyst on laparotomy. This patients has been managed successfully with some conservative treatment on and off during the course of pregnancy. With close supervision and expertise in the field of obstetrics and gynecology can give successful outcome in pregnancies. The aim is to give good maternal and the fetal outcome. In our case even though the left ovary was adherent to the cyst it was preserved successfully.

\section{REFERENCES}

1. Kiseli M, Caglar GS, Cengiz SD, Karadag D, Yilmaz MB. Clinical diagnosis and complications of paratubal cysts: Review of the literature and report of uncommon cases. Arch Gynecol Obstet 2012, 285: 1563-69.

2. Damle F, Gomez-Lobo V. Giant paraovarian cysts in young adolescents: a report of three cases. J Reprod Med 2012, 57: 65-7.

3. Barloon TJ, Brown BP, Abu-Yousef MM, Warnock NG. Paraovarian and paratubal cysts: preoperative diagnosis using transabdominal and transvaginal sonography. J Clin Ultrasound. 1966;24:117-22.

4. Varras M, Akrivis C, Polyzos D, Frakala S, Samara C. A voluminous twisted paraovarian cyst in a 74year-old patient: case report and review of the literature. Clin Exp Obstet Gynecol. 2003;30:253-6.

5. Thakore SS, Chun MJ, Fitzpatrick K. Recurrent ovarian torsion due to paratubal cysts in an adolescent female. J Pediatr Adolesc Gynecol. 2012: 85-7. doi:10.1016/j.jpag.2011.10.012.

6. Suzuki S, Furukawa H, Kyozuka H, Watanabe T, Takahashi H, Fujimori K. Two cases of paraovarian tumor of borderline malignancy. J Obstet Gynaecol Res 2013;39:437-41.

7. Honore L, O'Hare K. Serous papillary neoplasms arisiring in paramesonephric paraovarian cysts. Acta Obstet Gyneco Scand 1980;59:525-8.

8. Stein AL, Koonings PP, Schlareth JB, et al. Relative frequency of malignant parovarian tumors: should parovarian tumors be aspirated? Obstet Gynecol 1990;75:1029-3.

9. Genardy R, Parmley T, Woodruff JD. The origin and clinic behaviour of the paraovarian tumor. Am J Obstet Gynecol 1977;129:873-80.

10. Kim JS, Woo SK, Suh SJ, Morettin LB. Sonographic diagnosis of paraovarian cysts: value of detecting a separate ipsilateral ovary. AJR Am J Roentgenol 1995;164:1441-4.

DOI: 10.5455/2320-1770.ijrcog20131255

Cite this article as: Katke RD, Pagare P, Raina J, Singh K. A rare case of successful pregnancy outcome with giant paraovarian cyst: a case report and review of literature. Int J Reprod Contracept Obstet Gynecol 2013;2:730-2. 